\title{
Non-invasive prenatal testing for fetal chromosome abnormalities: review of clinical and ethical issues
}

This article was published in the following Dove Press journal:

The Application of Clinical Genetics

4 February 2016

Number of times this article has been viewed

\author{
Jean Gekas ${ }^{1,2}$ \\ Sylvie Langlois ${ }^{3}$ \\ Vardit Ravitsky ${ }^{4}$ \\ François Audibert ${ }^{5}$ \\ David Gradus van den Berg ${ }^{6}$ \\ Hazar Haidar ${ }^{4}$ \\ François Rousseau ${ }^{2,7}$ \\ 'Prenatal Diagnosis Unit, Department \\ of Medical Genetics and Pediatrics, \\ Faculty of Medicine, Université \\ Laval, Québec City, QC, Canada; \\ ${ }^{2}$ Department of Medical Biology, $\mathrm{CHU}$ \\ de Québec, Québec City, QC, Canada: \\ ${ }^{3}$ Department of Medical Genetics, \\ University of British Columbia, \\ Vancouver, BC, Canada; ${ }^{4}$ Bioethics \\ Program, Department of Social \\ and Preventive Medicine, School of \\ Public Health, University of Montreal, \\ Montreal, QC, Canada; ${ }^{5}$ Department \\ of Obstetrics and Gynecology, \\ Hospital Sainte-Justine, Montreal, \\ QC, Canada; ${ }^{6}$ Department of Social \\ and Preventive Medicine, Faculty of \\ Medicine, Université Laval, Québec \\ City, QC, Canada; ${ }^{7}$ Department \\ of Molecular Biology, Medical \\ Biochemistry and Pathology, Faculty \\ of Medicine, Université Laval, Québec \\ City, QC, Canada
}

Correspondence: Jean Gekas Centre Hospitalier de l'Université Laval (CHUL), CHU de Québec, 2705

Boulevard Laurier, Bureau RC-9300, Sainte-Foy, GIV 4G2, Québec City, QC, Canada

Tel + I 4185254444 ext $48 \mid$ I 4

$\mathrm{Fax}+\mathrm{I} 4186542748$

Email jean.gekas@mail.chuq.qc.ca

\begin{abstract}
Genomics-based non-invasive prenatal screening using cell-free DNA (cfDNA screening) was proposed to reduce the number of invasive procedures in current prenatal diagnosis for fetal aneuploidies. We review here the clinical and ethical issues of cfDNA screening. To date, it is not clear how cfDNA screening is going to impact the performances of clinical prenatal diagnosis and how it could be incorporated in real life. The direct marketing to users may have facilitated the early introduction of cfDNA screening into clinical practice despite limited evidence-based independent research data supporting this rapid shift. There is a need to address the most important ethical, legal, and social issues before its implementation in a mass setting. Its introduction might worsen current tendencies to neglect the reproductive autonomy of pregnant women.
\end{abstract}

Keywords: prenatal diagnosis, Down syndrome, non-invasive prenatal testing, cell-free fetal DNA, informed consent, reproductive autonomy

\section{Background}

Current prenatal diagnosis (PD) for fetal aneuploidies generally relies on an initial noninvasive risk screening strategy after which women who are deemed to be at high risk are offered an invasive confirmatory test. More recently, the clinical implementation of new genomics-based non-invasive prenatal screening tests (NIPTs) using cell-free DNA (cfDNA) screening for fetal chromosomal aneuploidies is observed.

Down syndrome ([DS] trisomy 21) is the most common cause of intellectual disability worldwide, affects approximately 1:500 pregnancies and is seen in 1:800 to 1:1,000 live births. ${ }^{1}$ Genetic PD for DS, since its introduction in the late 1960s, has evolved significantly. In order to limit the number of invasive procedures (amniocentesis or chorionic villus sampling [CVS]) for definitive PD, which is associated classically with a one in 200 chance of fetal miscarriage ${ }^{2,3}$ and with recent data suggesting a one in 1,000 risk of fetal miscarriage, ${ }^{4}$ the majority of public current screening programs ${ }^{5}$ for DS generally combine initial non-invasive risk screening strategies. These procedures use maternal serum with or without ultrasound markers in a mathematical model to estimate an overall personal risk score for each woman for carrying a fetus with DS. Women who are deemed to be at high risk are then offered invasive PD. ${ }^{6}$ Consequently, the routine offer of medical tests to pregnant women is usually a twotier procedure, in many Western countries with a public health setting. However, in other countries or in the USA, prenatal screening is made available to (self-paying or insured) patients in accordance with professional guidelines. ${ }^{7}$ This may have been facilitated by direct marketing to patients ${ }^{8}$ and the introduction of new genomics-based 
NIPT using cfDNA screening which is currently not publicly funded in most jurisdictions. ${ }^{5}$ These tests have the potential to offer earlier results during pregnancy and to substantially reduce the number of invasive procedures. ${ }^{9,10}$

The main justification for offering prenatal genetic diagnosis is the promotion of reproductive autonomy and informed decision-making by pregnant women. Reproductive autonomy is of utmost importance in PD. ${ }^{11,12}$ Since there is no cure for DS, efficient prenatal screening and diagnosis enable couples to make informed reproductive choices. ${ }^{2}{ }^{13}$ PD differs from other diagnostic procedures in medicine insofar as most conditions tested cannot be cured or substantially alleviated and the only option following an undesired result is therefore to decide whether to accept the child's condition and prepare for his or her birth or to terminate the pregnancy. Consequently, the main reason for offering prenatal genetic testing is to enhance the reproductive autonomy of the pregnant woman and/or the couple..$^{11,12}$ Invasive genetic diagnosis, ${ }^{14}$ second-trimester ultrasound screening, ${ }^{15}$ and first-trimester risk assessment, ${ }^{16}$ were considered controversial at the time of their introduction but have since become important autonomy-enhancing strategies in obstetric practice. ${ }^{17,18}$ In a practice bulletin published in 2007, the American College of Obstetrics and Gynecology recommended that prenatal screening for aneuploidy should be offered to all women, regardless of age. ${ }^{19}$ Nevertheless, choices may be more limited in the context of a publicly funded screening program where costs are a constraining factor than in settings where women have to fully pay themselves. ${ }^{7,20}$

Routine PD schemes need to be refined to improve the care provided to pregnant women. Invasive PD, such as amniocentesis or CVS, which can be performed from the eleventh week gestation is costly and entails a significant fetal loss rate. ${ }^{21}$ Amniocentesis, which is performed more often than CVS, is generally delayed until after 15 weeks, with a 1- to 2-week turnaround time for results.

Current non-invasive risk screening identifies up to $90 \%$ of pregnancies with trisomies, with a screen-positive rate of $4 \%$ to $5 \%$ in the general population. ${ }^{22}$ However, many women will undergo invasive PD while not carrying an affected fetus. Only one per 15 to 20 invasive procedures reveal aneuploidy ${ }^{23}$ while this leads to one per $100(1 \%)$ to 1,000 $(0.1 \%)$ procedure-related losses of unaffected fetuses. ${ }^{3,4}$

Hence, either a more specific screening method (ie, with a lower rate of false positive results) or a reliable and convenient method for PD (ie, with a much smaller [or absent] risk of fetal loss) has long been sought. ${ }^{11}$ The objective is to significantly improve the care provided to pregnant women.

In this review, we critically assess the published literature on genomics-based noninvasive prenatal screening using cfDNA screening which is currently not publicly funded in most jurisdictions ${ }^{5}$ and produce an overview of clinical and ethical issues of this technology.

\section{Materials and methods Literature search}

This paper is part of PEGASUS project (PErsonalized Genomics for prenatal Aneuploidy Screening USing maternal blood, ClinicalTrials.gov identifier NCT01925742). This project has been approved by Quebec University Hospital (CHU de Québec) research ethical committee on July 15, 2013 (number: 13-06-1236).

Relevant citations were extracted from Embase, PubMed, Web of Science, and the Cochrane databases from inception to July 2015. We developed the search strategy through an iterative and collaborative process in close collaboration with PD specialists and clinical experts in laboratory medicine, genetics, and obstetrics, particularly for the development of the cfDNA screening strategy for chromosome abnormalities. The search strategy consisted of MeSH (medical subject heading) terms, Emtree terms, and keywords related to PD for fetal aneuploidy detection, non-invasive risk screening strategies, reproductive autonomy, informed consent in PD, cell-free fetal DNA, genomics-based non-invasive prenatal screening, clinical recommendations in PD, ethical, legal, and social issues in PD for chromosome abnormalities. Also, references from selected articles and related reviews underwent an exhaustive search. No language restriction was applied. Articles were screened by titles and abstracts, and full texts were reviewed by two reviewers (JG, DV) to determine eligibility. Disagreement was resolved by discussion with a third reviewer (FR).

\section{Study selection}

Observational studies, such as cohort or case control, and randomized controlled trials were included. Case reports were excluded. Citations without abstracts were rejected. For multiple publications of the same data set, only the most relevant study was included.

\section{Evidence}

cfDNA screening allows the study of fetal genomic DNA in maternal blood, thus using a less invasive procedure than 
amniocentesis or CVS, and shows potential for improving current PD schemes. The presence of cfDNA released by the fetus into the circulation of its mother was reported in $1997 .{ }^{24}$ By analyzing this source of fetal genetic material, obtainable through a blood sample from a pregnant woman, cfDNA screening has been developed ${ }^{25}$ and proposed as potentially changing the approach to PD for DS and other conditions such as other significant trisomies for chromosomes 13 and $18 .^{25-27}$

Initially, three published prospective studies each involving more than 500 high-risk pregnancies investigated the performance of cfDNA screening for $\mathrm{DS}^{28-30}$ with full karyotyping results available. They showed the possible clinical applicability of these methods. Over all, NIPT offers a detection rate more than $99 \%$ and a false positive rate under $0.5 \%$ in high-risk pregnancies. ${ }^{28-30}$ More recently, other clinical trials confirmed these results with many additional studies currently underway. ${ }^{5,31-33}$ cfDNA screening has also been proposed as a replacement for first level screening in both high and average risk population for DS, for some single gene disorders, determination of Rhesus D blood-group status, fetal sex pathologies, sub-chromosomal events, fetal DNA copy number variation, and genome-wide cell-free fetal DNA profiling. ${ }^{7,34-44}$ Nevertheless, cfDNA screening is not sufficiently sensitive and specific for a diagnostic test ${ }^{37,45-47}$ and cfDNA screening performance is better documented in trisomies 21 and 18 than for other trisomies. ${ }^{7,48}$

Professional groups have stated that cfDNA screening could be an option for prenatal fetal aneuploidy detection. Professional groups ${ }^{49-53}$ have published clinical recommendations regarding the use of cfDNA screening for fetal aneuploidy detection. Together, the American Congress of Obstetricians and Gynecologists, the National Coalition for Health Professional Education in Genetics and the National Society of Genetic Counselors in the USA, the International Society for Prenatal Diagnosis, the Society of Obstetricians and Gynecologists of Canada, and the California Technology Assessment Forum stated that cfDNA screening could be an option for fetal aneuploidy detection in high-risk pregnancies after non-directive counseling by qualified personnel. It is obvious that a shift has already started in the routine care of pregnancies. ${ }^{52,54}$ The American College of Medical Genetics and Genomics has not limited their recommendation to women at high risk for fetal chromosome abnormality in accordance with the health insurer Blue Cross. ${ }^{35,55}$ New clinical advances in cfDNA screening may necessitate clinical policy modifications for considering new potential uses and applications for other conditions..$^{5,56-58}$

\section{Limitations of cfDNA screening technologies in PD for fetal chromosomal abnormalities}

To date, while a reasonable amount of evidence supports the use of cfDNA screening in high-risk women for detection of fetal trisomies 21 and $18,{ }^{49-51}$ no studies have addressed the cost-effectiveness $(\mathrm{C} / \mathrm{E})$ of cfDNA screening implementation in a routine real life pregnancy health care workflow setting. One editorial analyzed some $\mathrm{C} / \mathrm{E}$ aspects of NIPT. ${ }^{59}$ Moreover, available C/E studies are simulation models sponsored by industry, performed for high-risk women ${ }^{60-62}$ or evaluated on the general population. ${ }^{63-66}$ One study reports that NIPT as a screening tool that requires a confirmatory amniocentesis would be cost-effective as compared with its use as a diagnostic tool, leading to far fewer losses of unaffected pregnancies. ${ }^{60}$ A second study concluded that NIPT would be cost-effective in high-risk patients (maternal age 35 or greater) with a lower total health care expenditure over both first-trimester and integrated non-invasive risk screening while improving DS detection and reducing euploid fetal losses. ${ }^{61,62}$ The studies done on the general population reported that cfDNA screening implementation would be economically justified ${ }^{63-66}$ but are simulation models too. Other data reported that this approach may become sufficiently cost-effective only by a significant reduction in the costs of cfDNA screening. ${ }^{67,68}$ In a recent simulation study, ${ }^{63}$ for the general pregnancy population, cfDNA screening is reported to identify $15 \%$ more trisomy cases, to reduce invasive procedures by $88 \%$, and reduce iatrogenic fetal loss by $94 \%$ as compared to first-trimester combined screening with serum markers and nuchal translucency evaluation by ultrasound. This approach, was also shown to be more cost-effective at a cost unit of US\$453 and below. ${ }^{63}$

Thus, no published study performed extensive $\mathrm{C} / \mathrm{E}$ analyses of this technology and of different screening algorithms using cfDNA screening. An independent comparative $\mathrm{C} / \mathrm{E}$ validation study is needed to further validate alternative NIPT methods, in both low- and high-risk women to optimally introduce this technology into routine workflow prenatal care in existing DS prenatal detection programs. ${ }^{3,8,11,62}$ Finally, this should be accompanied by the development of national best practice guidelines and standard laboratory protocols to ensure the equitable provision of high quality health services. ${ }^{7,11}$ 
Additionally, all major studies of cfDNA screening $28,30,69,70$ were industry-funded (Sequenom, Verinata Health, AriosaDx) and aimed mainly at validating the performance of cfDNA screening technology compared to invasive PD for trisomy 21 , trisomy 18 , and trisomy 13 . Even if these studies reported excellent performances, many elements need to be taken into consideration:

1) In the spectrum of evidence needed before introducing a new technology into routine clinical use, the availability of studies independent from the patent/license-holders is critical. ${ }^{71,72} \mathrm{~A}$ systematic review showed that diagnostic methods' performances tend to be overestimated in initial studies and studies funded by sponsors. ${ }^{73} \mathrm{C} / \mathrm{E}$ studies from sponsors were more likely to report more favorable $\mathrm{C} / \mathrm{E}$ ratios than independent studies. ${ }^{74}$ It is therefore important to independently assess and compare the analytical and clinical validity of these promising technologies for clinical use in real-world clinical settings and independently from the holders of the technology's patents. 2) The majority of available data addressed the diagnostic performances of cfDNA screening for fetal aneuploidies among women classified to be at high risk for fetal aneuploidy but data on the applicability of cfDNA screening in normal-risk pregnancies are more limited. ${ }^{7,38,39}$ Data obtained in a study evaluating NIPT for women who benefited from first-trimester combined tes ${ }^{37}$ showed interesting results but in $4.9 \%$ of women, results could not be issued. However, there is growing evidence that comparably good results can also be achieved in general obstetrical population with first-tier cfDNA screening ${ }^{7,34,37,39,75-77}$ Although ten times better than the positive predictive value (PPV) of current first-trimester screening in similar risk group, this is far below the near $100 \%$ required for trisomy 21 diagnosis. $^{7}$ More data are needed to confirm whether genomic cfDNA screening would be an effective approach in normal-risk pregnancies, notably because of its unknown PPV in this patient population. ${ }^{7}$ Even if a sensitivity exceeding $98 \%$ and a specificity above $99.5 \%$ is reported in cfDNA screening studies, ${ }^{22}$ there is a lack of information about the tests' PPV which reflects the probability that a positive test result indicates a true fetal aneuploidy. Although sensitivity and specificity are unaffected by the condition's prevalence in the test population, PPV and negative predictive value (NPV) vary considerably with prevalence. cfDNA screening studies ${ }^{22}$ have mostly been conducted in high-risk groups of women with prevalence rates for DS in the samples as high as one in eight. With a prevalence of one in eight, assuming a constant specificity of $99.7 \%$ and a sensitivity of $99.9 \%$, the PPV and NPV are impressively high (97.94\% and $99.99 \%)$, respec- tively. But at a prevalence of one in 200, or even one in 1,000, the approximate prevalence of DS in low-risk pregnancies in the second-trimester of pregnancy, the PPV drops below $63 \% .{ }^{22}$ It is estimated that in a general risk population, more than half of positive cfDNA screening results may be false positive tests. ${ }^{39}$ Even when offered to those at a very high a priori risk (one in five), the PPV does not exceed 99\%, ${ }^{22}$ this is why a positive cfDNA screening result should always be confirmed by an amniocentesis. ${ }^{7}$ The lower prevalence of trisomies 18 and 13 in a general population (respectively 2.3 in 10,000 and 1.4 in 10,000) will affect the PPV for these conditions. ${ }^{78,79}$ By contrast, the NPV increases with lower a priori risk. This means that except for women classified at high risk for trisomies 21,18 , or 13 , a negative cfDNA screening result is highly reliable. ${ }^{7,22} 3$ ) False positive and false-negative cfDNA screening results may occur at a higher rate than previously reported in clinical trials. ${ }^{8,80,81}$ There is less evidence on the efficacy of the use of cfDNA screening for trisomy 13, sex chromosomal aneuploidies and triploidies, ${ }^{7,25-27,48,82-97}$ while these common fetal chromosomal aneuploidies are targeted in conventional PD. However, it is estimated that technological improvements will overcome false-negative results obtained for triploidies, which are not currently picked up by cfDNA screening. ${ }^{88,89}$ False positive results have been reported because of confined placental mosaicism, a vanishing twin or a maternal tumor. ${ }^{8,37,90-93} \mathrm{In}$ published data, confined placental mosaicism is thought to occur in $1 \%-2 \%$ of CVS analyses ${ }^{8,94}$ but may be higher with one study showing $4.8 \%$ of term placentas with confined mosaicism. ${ }^{8,95}$ Tests also generally assume a normal maternal karyotype since low-level maternal mosaicism may impact cfDNA screening results. ${ }^{8,28}$ Sometimes false-negative results remain unexplained.$^{80}$ Additional research is needed assessing the impact of discordance among maternal, fetal, and placental chromosomes on cfDNA screening results especially as normal cfDNA screening results were not verified by invasive prenatal or post-delivery data in some studies. ${ }^{8,69,96,97}$ 4) It is not clear how cfDNA screening is going to perform in real life prenatal care. ${ }^{8}$ The rate of non-reportable results, depending on the inclusion criteria for pregnant women and technical protocol used, ranged from $1 \%$ to $5 \% .{ }^{28-30,45}$ Samples that do not meet quality control with low fetal fraction (under $4 \%$ ) or sampling errors are reported between 3\% and $7 \%$ of patients. ${ }^{8,29,30,69,70,98,99}$ Given that the performance of cfDNA screening has been shown to be dependent on the fetal fraction, ${ }^{69}$ most tests require a minimal fetal fraction to report a result. Although a number of factors may influence fetal fraction as testing occurs before 9 weeks, the most 
significant one has been shown to be maternal weight with a higher failure rate encountered among obese women probably due to a dilution effect and their increased adipocyte turnover. ${ }^{30,31,100}$ However, the exact predicted impact of body mass index on the ability of cfDNA screening to provide results is still unclear. More evidence about failure rates and risk factors for failed cfDNA screening is necessary. 5) There is limited evidence about the performance of cfDNA screening in twin or triplet pregnancies. ${ }^{101} 6$ ) Unlike other screening methods, cfDNA screening does not evaluate nuchal translucency, placenta function with biochemical markers, and does not detect neural tube defects. ${ }^{57,59,102}$ These biochemical markers are simultaneously used to test for pregnancy complication risks such as pre-eclampsia or intrauterine growth retardation. The role of first-trimester nuchal translucency measurement and conventional biochemical testing needs to be reassessed in the context of the use of cfDNA screening ${ }^{103}$ especially as, some specific concerns such as impact of cfDNA screening on prenatal ultrasound practice have already been expressed. ${ }^{104}$ In contrast, some reports published interesting results of using altered levels of cell-free fetal DNA as a marker for pregnancy complications or preterm birth. ${ }^{92,105}$ In the future, cfDNA screening might be used to also detect some pregnancy complications or fetal disorders. ${ }^{106}$ An ethical evaluation of the implications of these developments will be needed to distinguish between autonomy- and prevention-aimed screening considerations. ${ }^{7}, 106-108$ 7) Since cfDNA screening would be used to detect only trisomies 21,18 , and 13 , other clinically relevant chromosomal abnormalities would be missed. ${ }^{7,109}$

\section{How could cfDNA screening be incorporated into the framework of existing PD programs?}

With regard to the clinical implementation of cfDNA screening, three scenarios are possible: 1) NIPT might replace current screening approaches or be added to them (unique risk calculation including screening tests from existing prenatal screening programs for DS and NIPT based on cffDNA); 2) cfDNA screening might be interposed between current screening and invasive PD in order to filter out most of the screening false positives (added to a subset of women as for contingent screening); or 3) cfDNA screening might replace invasive PD if it is ever considered as a valid diagnostic test (if this technology is getting better), as opposed to a screening test. ${ }^{12,110}$

Which of these options is followed will depend primarily on the technical accuracy of NIPT strategies (in terms of sensitivity and specificity) observed in validation studies of normal risk women and the available resources. Nevertheless, replacing current screening programs for DS which consist of a multistep process with a single maternal blood test (the first option) would seem to be the most attractive, ${ }^{3,7,12}$ as this option may offer safer, earlier, and easier antenatal testing than current standard practices. Moreover, women's preferences regarding NIPT showed that the single most important factor for choosing NIPT was eliminating the risk of a procedure-related miscarriage (75\%) followed distantly by accuracy of results $(13 \%) .{ }^{111}$

Clinical implementation of cfDNA screening might worsen current tendencies to neglect the protection of reproductive autonomy of pregnant women. In the case of DS PD, where cfDNA screening would replace a probabilistic test with a single highly predictive test, the main ethical challenges for implementation are safeguarding patient autonomy and ensuring informed consent. . $-7,11,12,32,46,108,112-116$ Current screening programs for DS ensure a two-step procedure: non-invasive risk screening as a first step that is followed by counseling and discussion and an invasive procedure as a second step for women who choose it based on being classified as high risk for DS. In the third scenario (cfDNA screening replacing invasive PD), this two-step approach will be transformed into a one-step diagnostic procedure where offering the test and taking the test could occur at the same time, leaving little time for discussion or reflection. ${ }^{12}$ In the context of such a scenario, with one single contact between the pregnant woman and the physician to discuss the pros and cons of NIPT, women might find themselves overwhelmed with the information provided and may not be in a position to fully think about the implications of the test, which would undermine their informed decision-making. Thus, despite the numerous benefits of abolishing invasive PD and its associated risk of fetal loss, a one-step NIPT might worsen current tendencies to neglect the reproductive autonomy of pregnant women. ${ }^{12,20,117,118}$ Even if recommendations from professional groups have considered a limited implementation into the framework of existing prenatal screening programs for DS, these concerns are likely to become increasingly pressing if cfDNA screening becomes available for an increased number of women $(n=115)$.

Studies in many countries have provided similar results on the quality of informed consent in currently available multi-step procedures for DS prenatal screening. There is already a need to improve the quality of informed consent for existing multi-step prenatal genetic examinations ${ }^{13,119-121}$ and this need will become even more pressing if NIPT becomes a 
one-step procedure ${ }^{11,12}$ with an easy test that might take place in a mass screening setting and perhaps even in a direct-toconsumer context. Since the end of 2011, such tests have become clinically and commercially available in the USA, parts of Europe, Asia, Australia, and the Middle East. This technology is now advertised and marketed to health care providers and pregnant women, creating significant pressure for its introduction in prenatal care while all the usual validation studies have not yet been performed, and while other tools needed for implementation are neither validated nor available.

A recent study of clinicians has shown that health care providers viewed consent for non-invasive NIPT as less important that consent for invasive PD after current screening tests. ${ }^{122}$ To avert this pitfall, it is suggested to ensure an informed consent by keeping a two-step approach for NIPT with counseling in the first stage and decision-making followed by testing when appropriate in the second stage. ${ }^{11,12,112,117,123}$ At the same time, the feasibility of maintaining a two-step approach in a real-life setting is questionable.

Gaps that need to be tackled prior to the introduction of cfDNA screening in routine care workflow are: gap 1 is to obtain enough data, independent from industry, on the clinical performance and clinical utility of cfDNA screening in both normal- and high-risk women, especially as cfDNA screening clinical performance is not sufficiently demonstrated in normal-risk pregnancies. ${ }^{22}$

Recent concerns are expressed over the popularity and rapidly spreading use of cfDNA screening in routine prenatal care. One recent publication ${ }^{22}$ asks physicians to resist the pressure of rapid proliferation of cfDNA screening and believes that the minimal regulatory oversight on these technologies has led to these tests becoming routinely available ahead of accurate evidence being available to consumers and to the health care systems. Effectively, cfDNA screening is considered laboratory-developed tests that are produced by companies governed by Clinical Laboratory Improvement Amendments and not by the US Food and Drug Administration (FDA). Thus, the FDA is not authorized to demand evidence of clinical validity which is usually needed for marketing authorization. ${ }^{22}$ Another concern relates to aggressive marketing methods to push the use of cfDNA screening by consumers. . $^{72,124}$

Gap 2 is to ensure that tools are developed for appropriately counseling and informing women regarding cfDNA screening, for safeguarding patient autonomy, and ensuring informed consent. Since cfDNA screening will be offered to increasing numbers of women, it will significantly raise the need for counseling, ${ }^{122,125}$ a need that cannot be met even with regards to current screening tests. ${ }^{121,126}$ It may also impact the legal obligations of health care providers to offer testing. cfDNA screening therefore requires the development of appropriate tools for patient and provider education, counseling, informed decision-making, and consent (such as educational brochures, video capsules, and websites) to protect and promote reproductive autonomy. ${ }^{47,127}$ These tools should be creative and innovative; emphasize the role of obstetricians and primary care physicians rather than necessarily rely on traditional models developed for genetic counselors; and address the actual concerns of patients and clinicians, as well as concerns related to the social acceptance and impact of cfDNA screening. These tools should also address practical implementation concerns, such as whether the test should be offered and performed on 2 different days in order to create "space" for reflection and consideration. Ideally, tools measuring informed choices have to be developed and validated in routine prenatal care of pregnancies. .,128,129 $^{2}$

Specific attention should be given to consent in the context of possible incidental findings through cfDNA screening. For example, we have to resolve the issue of the inadvertent discovery of sex chromosome aneuploidy in the context of a test being done to screen for DS. Inadvertent discovery of sex chromosome aneuploidy was not infrequent in the last decades when genetic PD routinely involved testing by an invasive procedure such as CVS and amniocentesis, done in the majority of cases for advanced maternal age. This is much less common because relatively few pregnancies are tested without prior prenatal screening, which is not designed to identify sex chromosome aneuploidies. Thus, inadvertent discovery of a sex chromosome aneuploidy has significantly decreased. ${ }^{23}$ If cfDNA screening replaces current screening approaches with a high uptake rate and vendors offer information on sex chromosome aneuploidy, the inadvertent discovery of sex chromosome aneuploidy might become common because of the high incidence of sex chromosome abnormalities at birth ${ }^{23}$ and sex chromosome aneuploidy such as $47, \mathrm{XXY}$ is favored by advanced maternal age. Nowadays in the USA, companies are offering cfDNA screening for trisomy 21 and provide information on $\mathrm{X}$-aneuploidy. ${ }^{23}$

Hence, routine PD schemes need to be refined if cfDNA screening is implemented in a mass setting and such issues should be addressed by ensuring that women and/or couples give specific consent to receiving different types of results, so that information such as the diagnosis of sex chromosome aneuploidy is not given inadvertently, but rather only given based on the expressed wishes of the woman to receive it. 
Gap 3 is the need to identify and address the most important ethical, legal, and social issues surrounding the implementation of cfDNA screening. cfDNA screening will offer risk-free, easy and early access to desired predictive genetic information and as such it would offer numerous benefits to women and their families. It is therefore expected that it will become a routine element of prenatal care with a high uptake. This expected "routinization" of NIPT raises concerns regarding increased social pressure to test and to terminate affected pregnancies as an expression of "responsible motherhood". The future widespread availability of cfDNA screening may lead to an implicit ethical, and perhaps even legal, obligation to test and consequently to the notion that women are "responsible for bearing a child with a disability" because they had information about the genetic status of their fetus and still chose to carry their pregnancy to term. ${ }^{114}$ Genetic counseling is traditionally non-directive, but pre-test counseling for cfDNA screening will be provided by health professionals without specific training in genetics. One of the challenges will be to ensure that the discussion of DS and other conditions remains balanced. ${ }^{130,131}$

Moreover, the routinization of a better technology to screen (cfDNA screening) may lead to an increase in the diagnoses of DS during the prenatal period. This may lead, even by ameliorating the parents' reproductive autonomy, more often to offering the choice of a pregnancy termination to parents implicated in the process. This may result in decreased prevalence of individuals with DS in the population which raises concerns regarding stigmatization, discrimination, and the decrease in support systems for individuals with disabilities. ${ }^{6,47,126,132,133}$ These concerns may adversely affect the social acceptability of cfDNA screening and will have to be addressed as the technology is introduced and implemented, possibly by addressing legal challenges and proposing policy and regulatory mechanisms.

Finally, the risk-free nature of NIPT, combined with the ability to test earlier in the pregnancy, might lower the threshold for appropriate testing. Invasive testing is only carried out for conditions that are perceived as severe enough to justify the risk of miscarriage. In the absence of risk, individuals may wish to test for less severe conditions, for late-onset conditions, for non-medical information such as sex and paternity, and perhaps for physical or - in the more distant future - even behavioral traits. ${ }^{134}$ Sex selection and paternity testing, ${ }^{114,135,136}$ raise particular concerns in countries such as India ${ }^{137}$ and People's Republic of China, ${ }^{138}$ where a skewed sex ratio has led to legal prohibition of prenatal fetal sex determination for non-clinical indications. ${ }^{7}{ }^{739}$ Forbidding sex selection for non-medical reasons as organized in context of medically assisted reproduction may be useful. ${ }^{7,140}$ Such trends raise ethical and social concerns that may have to be addressed through policy making. Especially, it is expected to become technically possible to screen by this technology beyond chromosomal abnormalities also Mendelian disorders and other fetal genetic disorders in the future. ${ }^{7,141}$ However, expansion of the practice would bring new ethical issues. ${ }^{7,108,134}$ Concerns about wider testing included a slippery slope toward testing for minor abnormalities or cosmetics traits. ${ }^{7117,142}$ Notably it may be more difficult for pregnant women to make meaningful reproductive choices with variants of uncertain clinical significance, unexpected genetic disorders, adult-onset conditions and carrier status. ${ }^{20,134,143}$ Ethical aspects of offering prenatal testing for new specific conditions are matters for further research and debate. ${ }^{7,144}$ Curiosity for fetal genome scans needs to be balanced with the risk of exposing the future child to possibly harmful information. ${ }^{7,134}$ If a screening procedure is used for two different aims, (detection of fetal anomalies and pregnancy-related problems), non-directive counseling for respecting reproductive autonomy would no longer be taken as a standard. ${ }^{6}$ Also, meaningful reproductive choices accepted by the taxpayers when prenatal screening for fetal disorders is publicly funded should be defined. ${ }^{7}$

\section{Conclusion}

The diffusion of cfDNA screening into routine prenatal care is a major breakthrough in prenatal screening and diagnosis, notably because, this technology has the potential to offer earlier results in the first-trimester without multiple blood samples and substantially reducing the number of invasive procedures. ${ }^{9}{ }^{910} \mathrm{~A}$ recent overview of cfDNA screening used in clinical practice seems to confirm this in real life. ${ }^{145}$ However, its integration may be occurring too quickly. The direct marketing to patients and end-users may have facilitated the early introduction of cfDNA screening into clinical practice despite limited evidence based research data supporting this rapid shift. ${ }^{8}$ Recent data showed a widespread offer of this technology in clinical practice but differences in service provision, emphasizing the need for guidelines that can harmonize practice. ${ }^{146}$ Significant maternal, provider, and regional differences in the uptake of prenatal screening exist with discrepancies expected to increase with the emergence of cfDNA screening. A pilot study already reported that there was a significant reduction in the number of patients referred for genetic counseling following the introduction of NIPT potentially leading to misdiagnosis of some fetal 
single gene disorders and aneuploidies not detectable by cfDNA screening. ${ }^{147}$

Even if it might be argued that asking women to pay for a prenatal screening test increases the awareness that there is truly a choice to be made, the need to pay may limit the access to prenatal screening to those who are able to pay, creating an issue of justice. ${ }^{7,148} \mathrm{~A}$ pilot study seems to confirm that an inequity of access due to cost was the most common ethical issue encountered. ${ }^{149}$

Limitations of cfDNA screening may be underappreciated by providers and patients. ${ }^{150,151}$ As with many medical innovations, physicians will have to resist pressures to promote the unwarranted use of cfDNA screening due to aggressive marketing and the rapid proliferation of direct-to-consumer services. ${ }^{8,22,95}$ There is ample evidence that a premature introduction of new health technologies (ie, prior to the availability of a strong evidence-base) can be not only expensive, but also deleterious to the health of patients..$^{152-154}$

Because of public budgetary constraints, implementing cfDNA screening as a first-tier test in a fully funded screening program may be difficult without the cost per unit being brought down significantly. ${ }^{7,15-157}$ At this time, the promising performance of cfDNA screening has been reported in highrisk pregnancies only for trisomies 21 and 18 . This additional screening test may be an option for women classified as highrisk of aneuploidy who wish to avoid invasive diagnostic tests if the ultrasound examination is normal. ${ }^{158}$ Nevertheless, cfDNA screening should not currently be used as a first-tier prenatal screening test for DS, because its clinical validity and clinical utility have not yet been shown without any doubt in pregnant women of average risk and is not recommended by the majority of professional societies. ${ }^{7,159}$ Also, since there is less evidence on the efficacy of the use of cfDNA screening for chromosome anomalies other than trisomies 21 and 18 and cfDNA screening does not detect all chromosomal anomalies identified by a fetal karyotype or microarray, ${ }^{23,160}$ amniocentesis should remain accessible for women classified as high-risk for a fetal aneuploidy because of a suggestive ultrasound finding.

Finally, for the moment, cfDNA screening is considered as a screening test and not as a diagnostic test. This means that a positive cfDNA screening result should always be confirmed by an invasive test such as amniocentesis or CVS. ${ }^{\text {? }}$ In this context, it is crucial that providers carefully counsel patients about the test's advantages and limitations. Especially, the possibility to screen by cfDNA a large range of genetic disorders such as submicroscopic abnormalities and genome mutations is expected in coming years. ${ }^{161-164}$ Nevertheless, for these new screened genetic disorders, the PPV is expected to be low, ${ }^{164}$ many of these are associated with unknown clinical significance with counseling challenges and burdening women with difficult decision-making ${ }^{165}$ and in some studies the false positive rate is reported as high as $3 \%$., 766

\section{Acknowledgments}

The authors are members of the research Team of the PEGASUS project, funded mainly by Genome Canada, the Canadian Institutes for Health Research, Genome Québec, Genome BC, Genome Alberta, the Ministry of Higher Education, Research, Science and Technology of Quebec.

In 2013 our team of researchers led by Dr Francois Rousseau from Universite Laval and Dr Sylvie Langlois, University of British Columbia, received CAN\$10.5 million from Genome Canada, the Canadian Institutes of Health Research (CIHR), Genome Quebec to conduct, to our knowledge, the first public independent from industry, large-scale comparative effectiveness study on non-invasive prenatal screening techniques.

The project involves an interdisciplinary team of 27 researchers from 12 universities (eight in Canada, four in Europe - and five federal and provincial policy makers in the health care field). All the authors of the paper are part of this research project: PEGASUS (PErsonalized Genomics for prenatal Aneuploidy Screening USing maternal blood, ClinicalTrials.gov identifier NCT01925742).

\section{Disclosure}

FR holds an MSSS/FRQS/CHUQ Research Chair in Technology Assessment and Evidence-Based Laboratory Medicine. The authors report no other conflicts of interest in this work.

\section{References}

1. Greydanus DE, Pratt HD. Syndromes and disorders associated with mental retardation. Indian J Pediatr. 2005;72(10):859-864.

2. Chitayat D, Langlois S, Wilson RD. Prenatal screening for fetal aneuploidy in singleton pregnancies. J Obstet Gynaecol Can. 2011; 33(7):736-750.

3. Wright CF, Burton $H$. The use of cell-free fetal nucleic acids in maternal blood for non-invasive prenatal diagnosis. Hum Reprod Update. 2009;15(1):139-151.

4. Akolekar R, Beta J, Picciarelli G, Ogilvie C, D'Antonio F. Procedurerelated risk of miscarriage following amniocentesis and chorionic villus sampling: a systematic review and meta-analysis. Ultrasound Obstet Gynecol. 2015;45(1):16-26.

5. Vanstone M, King C, de Vrijer B, Nisker J. Non-invasive prenatal testing: ethics and policy considerations. J Obstet Gynaecol Can. 2014; 36(6):515-526.

6. de Jong A, Maya I, van Lith JM. Prenatal screening: current practice, new developments, ethical challenges. Bioethics. 2015;29(1):1-8.

7. Dondorp W, de Wert G, Bombard Y, et al. Non-invasive prenatal testing for aneuploidy and beyond: challenges of responsible innovation in prenatal screening. Eur J Hum Genet. 2015;23(11):1592. 
8. Lutgendorf MA, Stoll KA, Knutzen DM, Foglia LM. Noninvasive prenatal testing: limitations and unanswered questions. Genet Med. 2014;16(4):281-285.

9. Sehnert AJ, Rava RP, Bianchi DW. A new era in noninvasive prenatal testing. N Engl J Med. 2013;369(22):2164-2165.

10. Ashwood ER, Palomaki GE. A new era in noninvasive prenatal testing. N Engl J Med. 2013;369(22):2164.

11. Wright CF, Chitty LS. Cell-free fetal DNA and RNA in maternal blood: implications for safer antenatal testing. BMJ. 2009;339:b2451.

12. Schmitz D, Netzer C, Henn W. An offer you can't refuse? Ethical implications of non-invasive prenatal diagnosis. Nat Rev Genet. 2009; 10(8):515.

13. Gekas J, Gagne G, Bujold E, et al. Comparison of different strategies in prenatal screening for Down's syndrome: cost effectiveness analysis of computer simulation. BMJ. 2009;338:b138.

14. Druzin ML, Chervenak F, McCullough LB, Blatman RN, Neidich JA. Should all pregnant patients be offered prenatal diagnosis regardless of age? Obstet Gynecol. 1993;81(4):615-618.

15. Chervenak FA, McCullough LB, Chervenak JL. Prenatal informed consent for sonogram: an indication for obstetric ultrasonography. Am J Obstet Gynecol. 1989;161(4):857-860.

16. Chasen ST, Skupski DW, McCullough LB, Chervenak FA. Prenatal informed consent for sonogram: the time for first-trimester nuchal translucency has come. J Ultrasound Med. 2001;20(11):1147-1152.

17. Ewigman B, LeFevre M, Bain RP, Crane JP, McNellis D. Ethics and routine ultrasonography in pregnancy. Am J Obstet Gynecol. 1990; 163(1 Pt 1):256-258.

18. Wald N. First-trimester nuchal translucency screening. J Ultrasound Med. 2002;21(4):481; author reply 483-487.

19. ACOG Committee on Practice Bulletins. ACOG Practice Bulletin No 77: screening for fetal chromosomal abnormalities. Obstet Gynecol. 2007;109(1):217-227.

20. Hewison J. Psychological aspects of individualized choice and reproductive autonomy in prenatal screening. Bioethics. 2015;29(1):9-18.

21. Mujezinovic F, Alfirevic Z. Procedure-related complications of amniocentesis and chorionic villous sampling: a systematic review. Obstet Gynecol. 2007;110(3):687-694.

22. Morain S, Greene MF, Mello MM. A new era in noninvasive prenatal testing. N Engl J Med. 2013;369(6):499-501.

23. Simpson JL, Samango-Sprouse C. Prenatal diagnosis and 47,XXY. Am J Med Genet C Semin Med Genet. 2013;163C(1):64-70.

24. Lo YM, Corbetta N, Chamberlain PF, et al. Presence of fetal DNA in maternal plasma and serum. Lancet. 1997;350(9076):485-487.

25. Chiu RW, Chan KC, Gao Y, et al. Noninvasive prenatal diagnosis of fetal chromosomal aneuploidy by massively parallel genomic sequencing of DNA in maternal plasma. Proc Natl Acad Sci USA. 2008;105(51):20458-20463.

26. Chiu RW, Sun H, Akolekar R, et al. Maternal plasma DNA analysis with massively parallel sequencing by ligation for noninvasive prenatal diagnosis of trisomy 21. Clin Chem. 2010;56(3):459-463.

27. Fan HC, Blumenfeld YJ, Chitkara U, Hudgins L, Quake SR. Noninvasive diagnosis of fetal aneuploidy by shotgun sequencing DNA from maternal blood. Proc Natl Acad Sci U S A. 2008;105(42):16266-16271.

28. Bianchi DW, Platt LD, Goldberg JD, et al. Genome-wide fetal aneuploidy detection by maternal plasma DNA sequencing. Obstet Gynecol. 2012;119(5):890-901.

29. Norton ME, Brar H, Weiss J, et al. Non-Invasive Chromosomal Evaluation (NICE) Study: results of a multicenter prospective cohort study for detection of fetal trisomy 21 and trisomy 18. Am J Obstet Gynecol. 2012;207(2):137. e1-e8.

30. Palomaki GE, Kloza EM, Lambert-Messerlian GM, et al. DNA sequencing of maternal plasma to detect Down syndrome: an international clinical validation study. Genet Med. 2011;13(11):913-920.

31. Ashoor G, Syngelaki A, Poon LC, Rezende JC, Nicolaides KH. Fetal fraction in maternal plasma cell-free DNA at 11-13 weeks' gestation: relation to maternal and fetal characteristics. Ultrasound Obstet Gynecol. 2013;41(1):26-32.
32. Swanson A, Sehnert AJ, Bhatt S. Non-invasive Prenatal Testing: Technologies, Clinical Assays and Implementation Strategies for Women's Healthcare Practitioners. Curr Genet Med Rep. 2013; $1(2): 113-121$.

33. Vahanian SA, Baraa Allaf M, Yeh C, Chavez MR, Kinzler WL, Vintzileos AM. Patient acceptance of non-invasive testing for fetal aneuploidy via cell-free fetal DNA. J Matern Fetal Neonatal Med. 2014;27(1):106-109.

34. Fairbrother G, Johnson S, Musci TJ, Song K. Clinical experience of noninvasive prenatal testing with cell-free DNA for fetal trisomies 21, 18, and 13 , in a general screening population. Prenat Diagn. 2013;33(6):580-583.

35. Gregg AR, Gross SJ, Best RG, et al. ACMG statement on noninvasive prenatal screening for fetal aneuploidy. Genet Med. 2013; 15(5):395-398.

36. Lench N, Barrett A, Fielding S, et al. The clinical implementation of non-invasive prenatal diagnosis for single-gene disorders: challenges and progress made. Prenat Diagn. 2013;33(6):555-562.

37. Nicolaides KH, Syngelaki A, Ashoor G, Birdir C, Touzet G. Noninvasive prenatal testing for fetal trisomies in a routinely screened first-trimester population. Am J Obstet Gynecol. 2012;207(5):374. e1-e6.

38. Norton ME, Jacobsson B, Swamy GK, et al. Cell-free DNA analysis for noninvasive examination of trisomy. $N$ Engl J Med. 2015; 372(17):1589-1597.

39. Bianchi DW, Parker RL, Wentworth J, et al. DNA sequencing versus standard prenatal aneuploidy screening. $N$ Engl J Med. 2014;370(9):799-808.

40. Daley R, Hill M, Chitty LS. Non-invasive prenatal diagnosis: progress and potential. Arch Dis Child Fetal Neonatal Ed. 2014; 99(5):F426-F430.

41. Hume JH, Wardrop J, Boomer T, et al. Clinical outcome of subchromosomal events detected by whole-genome noninvasive prenatal testing. Prenat Diagn. 2015;35(10):999-1004.

42. Li R, Wan J, Zhang Y, et al. Detection of Fetal Copy Number Variations by Noninvasive Prenatal Testing for Common Aneuploidies. Ultrasound Obstet Gynecol. Epub 2015 May 29.

43. Brady P, Brison N, Van Den Bogaert K, et al. Clinical implementation of NIPT - technical and biological challenges. Clin Genet. Epub 2015 Apr 13.

44. Zhao C, Tynan J, Ehrich M, et al. Detection of fetal subchromosomal abnormalities by sequencing circulating cell-free DNA from maternal plasma. Clin Chem. 2015;61(4):608-616.

45. Benn P, Cuckle H, Pergament E. Non-invasive prenatal testing for aneuploidy: current status and future prospects. Ultrasound Obstet Gynecol. 2013;42(1):15-33

46. Davis DS. Opportunistic testing: the death of informed consent? Health Matrix Clevel. 2013;23(1):35-54.

47. de Jong A, Dondorp WJ, de Die-Smulders CE, Frints SG, de Wert GM. Non-invasive prenatal testing: ethical issues explored. Eur J Hum Genet. 2010;18(3):272-277.

48. Gekas J, Langlois S, Ravitsky V, et al. Identification of trisomy 18, trisomy 13, and Down syndrome from maternal plasma. Appl Clin Genet. 2014;7:127-131.

49. nchpeg.org [homepage on the Internet]. National Coalition for Health Professional Education in Genetics. Non-Invasive Prenatal Testing (NIPT) Factsheet. NCHPEG; 2012. Available from: http://www.nchpeg.org/ index.php?option $=$ com_content $\&$ view $=$ article $\&$ id $=384 \&$ Itemid $=255$. Accessed November 6, 2015.

50. Benn P, Borell A, Chiu R, et al. Position statement from the Aneuploidy Screening Committee on behalf of the Board of the International Society for Prenatal Diagnosis. Prenat Diagn. 2013;33(7):622-629.

51. California Technology Assessment Forum. Fetal Aneuploidy Detection Via Maternal Plasma DNA Sequencing, part 2. CTAF; 2012. Available from: http://www.ctaf.org/assessments/fetal-aneuploidy-detection-maternalplasma-dna-sequencing-part-2. Accessed November 6, 2015.

52. American College of Obstetricians and Gynecologists Committee on Genetics. Committee Opinion No 545: Noninvasive prenatal testing for fetal aneuploidy. Obstet Gynecol. 2012;120(6):1532-1534. 
53. Chromosomal Abnormality using Maternal Plasma DNA. Scientific Impact Paper No15 [Internet]. 2014 [cited March 2014].

54. Langlois S, Brock JA, Wilson RD, et al. Current status in non-invasive prenatal detection of down syndrome, trisomy 18, and trisomy 13 using cell-free DNA in maternal plasma. J Obstet Gynaecol Can. 2013;35(2):177-181.

55. BlueCross BlueShield Association. Sequencing-based tests to determine fetal down syndrome (trisomy 21) from maternal plasma DNA. Technol Eval Cent Assess Program Exec Summ. 2013;27(10):1-6.

56. Twiss P, Hill M, Daley R, Chitty LS. Non-invasive prenatal testing for Down syndrome. Semin Fetal Neonatal Med. 2014;19(1):9-14.

57. Hui L, Hyett J. Noninvasive prenatal testing for trisomy 21: challenges for implementation in Australia. Aust N Z J Obstet Gynaecol. 2013; 53(5):416-424.

58. Benn PA, Chapman AR. Practical and ethical considerations of noninvasive prenatal diagnosis. JAMA. 2009;301(20):2154-2156.

59. Chitty LS, Hill M, White H, Wright D, Morris S. Noninvasive prenatal testing for aneuploidy-ready for prime time? Am J Obstet Gynecol. 2012;206(4):269-275.

60. Ohno M, Caughey A. The role of noninvasive prenatal testing as a diagnostic versus a screening tool - a cost-effectiveness analysis. Prenat Diagn. 2013;33(7):630-635.

61. Song K, Musci TJ, Caughey AB. Clinical utility and cost of noninvasive prenatal testing with cfDNA analysis in high-risk women based on a US population. J Matern Fetal Neonatal Med. 2013;26(12): $1180-1185$.

62. Morris S, Karlsen S, Chung N, Hill M, Chitty LS. Model-based analysis of costs and outcomes of non-invasive prenatal testing for Down's syndrome using cell free fetal DNA in the UK National Health Service. PLoS One. 2014;9(4):e93559.

63. Fairbrother G, Burigo J, Sharon T, Song K. Prenatal screening for fetal aneuploidies with cell-free DNA in the general pregnancy population: a cost-effectiveness analysis. J Matern Fetal Neonatal Med. 2015: $1-5$.

64. Benn P, Curnow KJ, Chapman S, Michalopoulos SN, Hornberger J, Rabinowitz M. An Economic Analysis of Cell-Free DNA Non-Invasive Prenatal Testing in the US General Pregnancy Population. PLoS One. 2015;10(7):e0132313.

65. Walker BS, Jackson BR, LaGrave D, Ashwood ER, Schmidt RL. A cost-effectiveness analysis of cell free DNA as a replacement for serum screening for Down syndrome. Prenat Diagn. 2015;35(5):440-446.

66. Walker BS, Nelson RE, Jackson BR, Grenache DG, Ashwood ER, Schmidt RL. A Cost-Effectiveness Analysis of First Trimester NonInvasive Prenatal Screening for Fetal Trisomies in the United States. PLoS One. 2015;10(7):e0131402.

67. Ayres AC, Whitty JA, Ellwood DA. A cost-effectiveness analysis comparing different strategies to implement noninvasive prenatal testing into a Down syndrome screening program. Aust NZJ Obstet Gynaecol. 2014;54(5):412-417.

68. Okun N, Teitelbaum M, Huang T, Dewa CS, Hoch JS. The price of performance: a cost and performance analysis of the implementation of cell-free fetal DNA testing for Down syndrome in Ontario, Canada. Prenat Diagn. 2014;34(4):350-356.

69. Chiu RW, Akolekar R, Zheng YW, et al. Non-invasive prenatal assessment of trisomy 21 by multiplexed maternal plasma DNA sequencing: large scale validity study. $B M J .2011 ; 342: c 7401$.

70. Ehrich M, Deciu C, Zwiefelhofer T, et al. Noninvasive detection of fetal trisomy 21 by sequencing of DNA in maternal blood: a study in a clinical setting. Am J Obstet Gynecol. 2011;204(3):205.e1-e11.

71. Peredo EL, Les DH, King UM, Benoit LK. Extreme conservation of the $\mathrm{psaA} / \mathrm{psaB}$ intercistronic spacer reveals a translational motif coincident with the evolution of land plants. J Mol Evol. 2012;75(5-6):184-197.

72. Roseman M, Milette K, Bero LA, et al. Reporting of conflicts of interest in meta-analyses of trials of pharmacological treatments. JAMA. 2011;305(10):1008-1017.

73. Lumbreras B, Parker LA, Porta M, Pollan M, Ioannidis JP, Hernandez-Aguado I. Overinterpretation of clinical applicability in molecular diagnostic research. Clin Chem. 2009;55(4):786-794.
74. Bell CM, Urbach DR, Ray JG, et al. Bias in published cost effectiveness studies: systematic review. BMJ. 2006;332(7543):699-703.

75. Gil MM, Quezada MS, Bregant B, Ferraro M, Nicolaides KH. Implementation of maternal blood cell-free DNA testing in early screening for aneuploidies. Ultrasound Obstet Gynecol. 2013;42(1):34-40.

76. Quezada MS, Gil MM, Francisco C, Orosz G, Nicolaides KH. Screening for trisomies 21,18 and 13 by cell-free DNA analysis of maternal blood at 10-11 weeks' gestation and the combined test at 11-13 weeks. Ultrasound Obstet Gynecol. 2015;45(1):36-41.

77. Song Y, Liu C, Qi H, Zhang Y, Bian X, Liu J. Noninvasive prenatal testing of fetal aneuploidies by massively parallel sequencing in a prospective Chinese population. Prenat Diagn. 2013;33(7):700-706.

78. Savva GM, Walker K, Morris JK. The maternal age-specific live birth prevalence of trisomies 13 and 18 compared to trisomy 21 (Down syndrome). Prenat Diagn. 2010;30(1):57-64.

79. Verweij EJ, de Boer MA, Oepkes D. Non-invasive prenatal testing for trisomy 13: more harm than good? Ultrasound Obstet Gynecol. 2014;44(1):112-114

80. Hochstenbach R, Page-Christiaens GC, van Oppen AC, et al. Unexplained False Negative Results in Noninvasive Prenatal Testing: Two Cases Involving Trisomies 13 and 18. Case Rep Genet. 2015; 2015:926545

81. Ma J, Cram DS, Zhang J, Shang L, Yang H, Pan H. Birth of a child with trisomy 9 mosaicism syndrome associated with paternal isodisomy 9: case of a positive noninvasive prenatal test result unconfirmed by invasive prenatal diagnosis. Mol Cytogenet. 2015;8:44.

82. Lapaire O, Lu XY, Johnson KL, et al. Array-CGH analysis of cell-free fetal DNA in $10 \mathrm{~mL}$ of amniotic fluid supernatant. Prenat Diagn. 2007;27(7):616-621.

83. Wick JB, Johnson KJ, O'Brien J, Wick MJ. Second-trimester diagnosis of triploidy: a series of four cases. AJP Rep. 2013;3(1):37-40.

84. Samango-Sprouse C, Banjevic M, Ryan A, et al. SNP-based noninvasive prenatal testing detects sex chromosome aneuploidies with high accuracy. Prenat Diagn. 2013;33(7):643-649.

85. Wang Y, Chen Y, Tian F, et al. Maternal mosaicism is a significant contributor to discordant sex chromosomal aneuploidies associated with noninvasive prenatal testing. Clin Chem. 2014;60(1):251-259.

86. Yao H, Jiang F, Hu H, et al. Detection of fetal sex chromosome aneuploidy by massively parallel sequencing of maternal plasma DNA: initial experience in a Chinese hospital. Ultrasound Obstet Gynecol. 2014;44(1):17-24.

87. Bianchi DW, Parsa S, Bhatt S, et al. Fetal sex chromosome testing by maternal plasma DNA sequencing: clinical laboratory experience and biology. Obstet Gynecol. 2015;125(2):375-382.

88. Chiu RW, Lo YM. Noninvasive prenatal diagnosis empowered by highthroughput sequencing. Prenat Diagn. 2012;32(4):401-406.

89. Straver R, Sistermans EA, Reinders MJ. Introducing WISECONDOR for noninvasive prenatal diagnostics. Expert Rev Mol Diagn. 2014; 14(5):513-515.

90. Benn P, Borrell A, Crossley J, et al. Aneuploidy screening: a position statement from a committee on behalf of the Board of the International Society for Prenatal Diagnosis, January 2011. Prenat Diagn. 2011;31(6):519-522.

91. Bianchi DW, Wilkins-Haug L. Integration of noninvasive DNA testing for aneuploidy into prenatal care: what has happened since the rubber met the road? Clin Chem. 2014;60(1):78-87.

92. Taglauer ES, Wilkins-Haug L, Bianchi DW. Review: cell-free fetal DNA in the maternal circulation as an indication of placental health and disease. Placenta. 2014;35 Suppl:S64-S68.

93. Bianchi DW, Chudova D, Sehnert AJ, et al. Noninvasive Prenatal Testing and Incidental Detection of Occult Maternal Malignancies. JAMA. 2015;314(2):162-169.

94. Ledbetter DH, Zachary JM, Simpson JL, et al. Cytogenetic results from the US Collaborative Study on CVS. Prenat Diagn. 1992;12(5):317-345.

95. Stetten G, Escallon CS, South ST, McMichael JL, Saul DO, Blakemore KJ. Reevaluating confined placental mosaicism. Am J Med Genet A. 2004;131(3):232-239. 
96. Sparks AB, Wang ET, Struble CA, et al. Selective analysis of cell-free DNA in maternal blood for evaluation of fetal trisomy. Prenat Diagn. 2012;32(1):3-9.

97. Artan S, Basaran N, Hassa H, et al. Confined placental mosaicism in term placentae: analysis of 125 cases. Prenat Diagn. 1995; 15(12):1135-1142

98. Palomaki GE, Deciu C, Kloza EM, et al. DNA sequencing of maternal plasma reliably identifies trisomy 18 and trisomy 13 as well as Down syndrome: an international collaborative study. Genet Med. 2012;14(3):296-305.

99. Canick JA, Palomaki GE, Kloza EM, Lambert-Messerlian GM, Haddow JE. The impact of maternal plasma DNA fetal fraction on next generation sequencing tests for common fetal aneuploidies. Prenat Diagn. 2013;33(7):667-674.

100. Wang E, Batey A, Struble C, Musci T, Song K, Oliphant A. Gestational age and maternal weight effects on fetal cell-free DNA in maternal plasma. Prenat Diagn. 2013;33(7):662-666.

101. Huang X, Zheng J, Chen M, et al. Noninvasive prenatal testing of trisomies 21 and 18 by massively parallel sequencing of maternal plasma DNA in twin pregnancies. Prenat Diagn. 2014;34(4):335-340.

102. Hill M, Wright D, Daley R, et al. Evaluation of non-invasive prenatal testing (NIPT) for aneuploidy in an NHS setting: a reliable accurate prenatal non-invasive diagnosis (RAPID) protocol. BMC Pregnancy Childbirth. 2014;14:229.

103. Cuckle H, Benn P, Pergament E. Cell-free DNA screening for fetal aneuploidy as a clinical service. Clin Biochem. 2015;48(15):932-941.

104. Salomon LJ, Alfirevic Z, Audibert F, et al. ISUOG consensus statement on the impact of non-invasive prenatal testing (NIPT) on prenatal ultrasound practice. Ultrasound Obstet Gynecol. 2014;44(1):122-123.

105. Poon LC, Musci T, Song K, Syngelaki A, Nicolaides KH. Maternal plasma cell-free fetal and maternal DNA at 11-13 weeks' gestation: relation to fetal and maternal characteristics and pregnancy outcomes. Fetal Diagn Ther. 2013;33(4):215-223.

106. Bianchi DW. From prenatal genomic diagnosis to fetal personalized medicine: progress and challenges. Nat Med. 2012;18(7):1041-1051.

107. Jorgensen JM, Hedley PL, Gjerris M, Christiansen M. Including ethical considerations in models for first-trimester screening for pre-eclampsia. Reprod Biomed Online. 2014;28(5):638-643.

108. de Jong A, de Wert GM. Prenatal screening: an ethical agenda for the near future. Bioethics. 2015;29(1):46-55.

109. Petersen OB, Vogel I, Ekelund C, et al. Potential diagnostic consequences of applying non-invasive prenatal testing: population-based study from a country with existing first-trimester screening. Ultrasound Obstet Gynecol. 2014;43(3):265-271.

110. Deans Z, Newson AJ. Ethical considerations for choosing between possible models for using NIPD for aneuploidy detection. $J$ Med Ethics. 2012;38(10):614-618.

111. Tischler R, Hudgins L, Blumenfeld YJ, Greely HT, Ormond KE. Noninvasive prenatal diagnosis: pregnant women's interest and expected uptake. Prenat Diagn. 2011;31(13):1292-1299.

112. Schmitz D, Henn W, Netzer C. Commentary: No risk, no objections? Ethical pitfalls of cell-free fetal DNA and RNA testing. BMJ. 2009; 339:b2690

113. Wilson JM, Jungner YG. Principios y práctica de cribado de la población. [Principles and practice of mass screening for disease]. Bol Oficina Sanit Panam. 1968;65(4):281-393. Spanish.

114. Newson AJ. Ethical aspects arising from non-invasive fetal diagnosis. Semin Fetal Neonatal Med. 2008;13(2):103-108

115. Nicolaides KH, Wright D, Poon LC, Syngelaki A, Gil MM. First-trimester contingent screening for trisomy 21 by biomarkers and maternal blood cell-free DNA testing. Ultrasound Obstet Gynecol. 2013;42(1):41-50.

116. Comité Consultatif National d'Ethique pour les sciences de la vie et de la santé (France). Questions éthiques associées au développement des tests génétiques fotaux sur sang maternel. [Ethical issues associated with the development of fetal genetic testing from maternal blood]. Available from: http://www.ccne-ethique.fr/sites/default/ files/publications/avis-120.pdf. Accessed June 22th, 2015. French.
117. Lewis C, Silcock C, Chitty LS. Non-invasive prenatal testing for Down's syndrome: pregnant women's views and likely uptake. Public Health Genomics. 2013;16(5):223-232.

118. van Schendel RV, Kleinveld JH, Dondorp WJ, et al. Attitudes of pregnant women and male partners towards non-invasive prenatal testing and widening the scope of prenatal screening. Eur J Hum Genet. 2014;22(12):1345-1350.

119. bzga.de [homepage on the Internet]. Renner I. Experience of Pregnancy and Prenatal Diagnosis 2006. Available from: http://www.bzga.de/? uid $=25 \mathrm{~d} 093$ aacb9296ea646b087b68c27996\&id=medien\&sid $=88 \&$ $\mathrm{idx}=1496$. Accessed November 6, 2015.

120. Favre R, Duchange N, Vayssiere C, et al. How important is consent in maternal serum screening for Down syndrome in France? Information and consent evaluation in maternal serum screening for Down syndrome: a French study. Prenat Diagn. 2007;27(3):197-205.

121. Seavilleklein V. Challenging the rhetoric of choice in prenatal screening. Bioethics. 2009;23(1):68-77.

122. van den Heuvel A, Chitty L, Dormandy E, et al. Will the introduction of non-invasive prenatal diagnostic testing erode informed choices? An experimental study of health care professionals. Patient Educ Couns. 2010;78(1):24-28.

123. Chervenak FA, McCullough LB, Sharma G, Davis J, Gross S. Enhancing patient autonomy with risk assessment and invasive diagnosis: an ethical solution to a clinical challenge. Am J Obstet Gynecol. 2008;199(1):19. e1-e4.

124. Agarwal A, Sayres LC, Cho MK, Cook-Deegan R, Chandrasekharan S. Commercial landscape of noninvasive prenatal testing in the United States. Prenat Diagn. 2013;33(6):521-531.

125. Kooij L, Tymstra T, Berg P. The attitude of women toward current and future possibilities of diagnostic testing in maternal blood using fetal DNA. Prenat Diagn. 2009;29(2):164-168.

126. Greely HT. Get ready for the flood of fetal gene screening. Nature. 2011;469(7330):289-291.

127. Ravitsky V. Non-invasive prenatal diagnosis: an ethical imperative. Nat Rev Genet. 2009;10(10):733.

128. Ames AG, Metcalfe SA, Dalton Archibald A, Duncan RE, Emery J. Measuring informed choice in population-based reproductive genetic screening: a systematic review. Eur J Hum Genet. 2015;23(1):8-21.

129. van Agt HM, Korfage IJ, Essink-Bot ML. Interventions to enhance informed choices among invitees of screening programmes-a systematic review. Eur J Public Health. 2014;24(5):789-801.

130. Hippman C, Inglis A, Austin J. What is a "balanced" description? Insight from parents of individuals with down syndrome. $J$ Genet Couns. 2012;21(1):35-44.

131. Devers PL, Cronister A, Ormond KE, Facio F, Brasington CK, Flodman P. Noninvasive prenatal testing/noninvasive prenatal diagnosis: the position of the National Society of Genetic Counselors. J Genet Couns. 2013;22(3):291-295.

132. Chachkin CJ. What potent blood: non-invasive prenatal genetic diagnosis and the transformation of modern prenatal care. Am J Law Med. 2007;33(1):9-53.

133. Hall A, Bostanci A, Wright CF. Non-invasive prenatal diagnosis using cell-free fetal DNA technology: applications and implications. Public Health Genomics. 2010;13(4):246-255.

134. Deans Z, Clarke AJ, Newson AJ. For your interest? The ethical acceptability of using non-invasive prenatal testing to test 'purely for information'. Bioethics. 2015;29(1):19-25.

135. Skirton H, Patch C. Factors affecting the clinical use of non-invasive prenatal testing: a mixed methods systematic review. Prenat Diagn. 2013;33(6):532-541.

136. Hill M, Lewis C, Jenkins L, Allen S, Elles RG, Chitty LS. Implementing noninvasive prenatal fetal sex determination using cell-free fetal DNA in the United Kingdom. Expert Opin Biol Ther. 2012;12 Suppl 1: S119-S126.

137. George SM. Millions of missing girls: from fetal sexing to high technology sex selection in India. Prenat Diagn. 2006;26(7):604-609.

138. Lai-wan CC, Blyth E, Hoi-yan CC. Attitudes to and practices regarding sex selection in China. Prenat Diagn. 2006;26(7):610-613. 
139. Madan K, Breuning MH. Impact of prenatal technologies on the sex ratio in India: an overview. Genet Med. 2014;16(6):425-432.

140. Dondorp W, De Wert G, Pennings G, et al. ESHRE Task Force on ethics and Law 20: sex selection for non-medical reasons. Hum Reprod. 2013;28(6):1448-1454.

141. Kitzman JO, Snyder MW, Ventura M, et al. Noninvasive whole-genome sequencing of a human fetus. Sci Transl Med. 2012;4(137):137ra76.

142. Farrimond HR, Kelly SE. Public viewpoints on new non-invasive prenatal genetic tests. Public Underst Sci. 2013;22(6):730-744.

143. van El CG, Cornel MC, Borry P, et al. Whole-genome sequencing in health care. Recommendations of the European Society of Human Genetics. Eur J Hum Genet. 2013;21 Suppl 1:S1-S5.

144. Committee On Bioethics; Committee On Genetics and, American College Of Medical Genetics and, Genomics S, Ethical, Legal Issues C. Ethical and policy issues in genetic testing and screening of children. Pediatrics. 2013;131(3):620-622.

145. Warsof SL, Larion S, Abuhamad AZ. Overview of the impact of noninvasive prenatal testing on diagnostic procedures. Prenat Diagn. 2015;35(10):972-979.

146. Minear MA, Lewis C, Pradhan S, Chandrasekharan S. Global perspectives on clinical adoption of NIPT. Prenat Diagn. 2015; 35(10):959-967.

147. Williams J 3rd, Rad S, Beauchamp S, et al. Utilization of noninvasive prenatal testing: impact on referrals for diagnostic testing. Am JObstet Gynecol. 2015;213(1):102. e1-e6.

148. Munthe C. A new ethical landscape of prenatal testing: individualizing choice to serve autonomy and promote public health: a radical proposal. Bioethics. 2015;29(1):36-45.

149. Hui L, Teoh M, Piessens S, Walker SP. Early clinical experience of cell-free DNA-based aneuploidy screening: A survey of obstetric sonologists in Australia and New Zealand. Aust NZJ Obstet Gynaecol. 2015;55(2):138-143.

150. Norton ME, Rose NC, Benn P. Noninvasive prenatal testing for fetal aneuploidy: clinical assessment and a plea for restraint. Obstet Gynecol. 2013;121(4):847-850.

151. wsj.com [homepage on the Internet]. Weaver C. Tough calls on prenatal tests. Wall Street Journal; 2013. Available from: http://www.wsj. com/articles/SB10001424127887324883604578398791568615644. Accessed November 6, 2015.

152. Ioannidis JP. Biomarker failures. Clin Chem. 2013;59(1):202-204.

153. Dyer O. The challenge of doing less. BMJ. 2013;347:f5904.

154. Technologies de la santé et prise de décision. [Health technologies and decision making]. Organisation for Economic Co-operation and Development. In: Health Technologies and Decision Making. Paris: OECD Publishing; 2005:158. French.
155. Beulen L, Grutters JP, Faas BH, Feenstra I, van Vugt JM, Bekker MN. The consequences of implementing non-invasive prenatal testing in Dutch national health care: a cost-effectiveness analysis. Eur J Obstet Gynecol Reprod Biol. 2014;182:53-61.

156. Cuckle H, Benn P, Pergament E. Maternal cfDNA screening for Down syndrome--a cost sensitivity analysis. Prenat Diagn. 2013; 33(7):636-642.

157. Neyt M, Hulstaert F, Gyselaers W. Introducing the non-invasive prenatal test for trisomy 21 in Belgium: a cost-consequences analysis. BMJ Open. 2014;4(11):e005922.

158. Manegold-Brauer G, Berg C, FlockA, Ruland A, Gembruch U, GeipelA. Uptake of non-invasive prenatal testing (NIPT) and impact on invasive procedures in a tertiary referral center. Arch Gynecol Obstet. 2015;292(3):543-548.

159. Larion S, Warsof SL, Romary L, Mlynarczyk M, Peleg D, Abuhamad AZ. Association of combined first-trimester screen and noninvasive prenatal testing on diagnostic procedures. Obstet Gynecol. 2014; 123(6):1303-1310.

160. Wapner RJ, Martin CL, Levy B, et al. Chromosomal microarray versus karyotyping for prenatal diagnosis. $N$ Engl $J$ Med. 2012;367(23):2175-2184.

161. Hayden EC. Prenatal-screening companies expand scope of DNA tests. Nature. 2014;507(7490):19.

162. Lau TK, Jiang FM, Stevenson RJ, et al. Secondary findings from non-invasive prenatal testing for common fetal aneuploidies by whole genome sequencing as a clinical service. Prenat Diagn. 2013; 33(6):602-608.

163. Mazloom AR, Dzakula Z, Oeth P, et al. Noninvasive prenatal detection of sex chromosomal aneuploidies by sequencing circulating cell-free DNA from maternal plasma. Prenat Diagn. 2013;33(6):591-597.

164. Vora NL, O'Brien BM. Noninvasive prenatal testing for microdeletion syndromes and expanded trisomies: proceed with caution. Obstet Gynecol. 2014;123(5):1097-1099.

165. Crawford G, Foulds N, Fenwick A, Hallowell N, Lucassen A. Genetic medicine and incidental findings: it is more complicated than deciding whether to disclose or not. Genet Med. 2013;15(11):896-869.

166. Lo KK, Boustred C, Chitty LS, Plagnol V. RAPIDR: an analysis package for non-invasive prenatal testing of aneuploidy. Bioinformatics. 2014;30(20):2965-2967.
The Application of Clinical Genetics

\section{Publish your work in this journal}

The Application of Clinical Genetics is an international, peer-reviewed open access journal that welcomes laboratory and clinical findings in the field of human genetics. Specific topics include: Population genetics; Functional genetics; Natural history of genetic disease; Management of genetic disease; Mechanisms of genetic disease; Counseling and ethical

\section{Dovepress}

issues; Animal models; Pharmacogenetics; Prenatal diagnosis; Dysmorphology. The manuscript management system is completely online and includes a very quick and fair peer-review system, which is all easy to use. Visit http://www.dovepress.com/testimonials.php to read real quotes from published authors. 